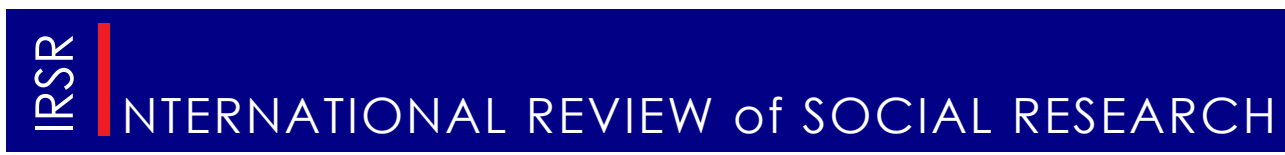

Volume 1, Issue 2, June 2011, 1-13

International Review of Social Research

\title{
Identity and the New Nationalist Pronouncements
}

\author{
Jean-Claude KAUFMANN* \\ National Center of Scientific Research (CNRS) \\ University Paris Descartes, The Research Centre on Social Relations CERLIS
}

\begin{abstract}
It is a common mistake to believe that identity deals with history, our memory, and our roots. While the center of identity-related processes is quite different, it cannot certainly ignore objective reality, and the individual's past. The inflationary use of the term dates only half a century back. Before that (except for administration) rarely was there any question of identity posed, because the individual was defined mainly by the institutional frameworks that determined him. The question of identity might have emerged gradually, as the gap widened, in the case of an individuality willing to be asserting itself as autonomous. First and foremost, it emerges out of subjectivity at work, with the purpose of making meaning which, in turn, is no longer conferred only by the social position occupied. It is an ever changing meaning, and in every instance a necessary condition of action. This is so because in a society dominated by reflexivity and critical thinking, the individual is persistently compelled to get involved in a cognitive functioning of the opposite type, in order to be able to act, creating small beliefs underlying personal evidences. At the heart of the most advanced modernity, the core of identity processes is, surprisingly, of a religious type. This process does not render itself evident in an isolated manner. Various affiliations (cultural, national, and religious) may be used, as well as many others resources, often mobile and diverse, which may turn into totalitarian, fixed, exclusive and sectarian statements. By such a framing of the entire landscape of the identity process, one may better understand the paradoxical situation of current nationalist expressions in Europe. They do not disappear, but sometimes even materialize into acute forms, even if the frameworks of socialization become increasingly transnational. It is precisely because the objective substrate of national identity is weakening, that its eruptive movements (during crises provoked by extremely different reasons) become unpredictable and uncontrollable and particularly dangerous for democracy.
\end{abstract}

Keywords: identity, individual, nationalism, belonging, modernity

Identity is a strange concept, and a very annoying one for scholars. As attractive as it appears, promising to point to primordial questions, its definition proves to be no less difficult. The more one seeks to describe it with precision, the less, generally, one succeeds. In one approach, Erving Goffman (who produced particularly subtle analyses of the self-defining process) compared

email: j-c.kaufmann@wanadoo.fr. 
it with a cotton candy; it is that 'sticky substance' that manages to pick up everything and twist everything around it (Goffman 1975: 74). Identity may quickly be found almost everywhere, and the inflation of its usage is impressive.

Faced with such a blur, with a polyphony of uses at the common sense level (and also in scientific literature) and in various radical ideological attitudes which claim identity to themselves, many researchers are tempted to turn away from this notion and use other concepts, which could be more seriously manageable. I am convinced that this would be an error, a scientific error. Identity has a lot to teach us, and we are definitely at the very beginning of understanding it. It is also a moral error, or if you prefer, a political one, because the stakes of defining identity are crucial for the future of the planet.

In his wonderful book, Passions and Interests, Albert Hirschman allows us to understand it, using another vague and central concept of the $17^{\text {th }}$ century: interest. He notes how much everybody used it (notably in philosophical debates), without defining it. He explains also why this ambiguity has played a foundational social role. It was the instrument that made it possible for market economy to be placed at Identity, Individual, Nationalism, Belonging, Modernity. The center of social regulation.

Currently, to a certain extent, the same happens with the notion of identity. Everybody uses it as if it was something obvious, while its ambiguous definition indicates, on the contrary, considerable political issues. Without seriously opening up the debate, opposing views are implicitly being used. I am convinced that this situation is unhealthy and full of potential implications, and that, conversely, it is necessary to open up and structure a debate in a rigorous manner. Scholars need to move out of the incorrectly taken-for-granted 'cotton candy' definition and also take up clear-cut positions in order to organize such a debate. That is what I will allow myself to do below.

In my opinion, three major errors have been committed in the current dominant understanding of the concept of identity.

\section{Three errors about identity}

The first one is to think that identity deals with history, our memory and our roots. In fact, it is exactly the opposite. The inflationary use of the term dates only half a century back: before that (except for administration) there was rarely any identity issue. This was precisely because the individual was one with his/her history and he/she was defined by institutional frameworks involved. The identity question emerged as the gap created by a subjectivity which imagined itself autonomous has widened. First and foremost, it is the result of subjectivity at work, whose aim is meaning production which is no longer conferred by the social position one occupies. This has involved not only finding the answer to the question 'Who am I?'; rather, it permeates every moment, and every decision making instance, even the most miniscule, which, altogether, engage full-blown ethics and worldview. Then 
and only then may various belongings (cultural, national, religious) be used as resources, which can, nonetheless, turn into sectarian and totalitarian claims.

I acknowledge that it is difficult to understand that identity is linked to subjectivity and production of meaning, rather than 'roots'. The counterargument one encounters is: 'Well, one has, after all, an age, gender and history!' This is the second mistake. It is to mix up the administrative identity, grounded on the objective reality of the individual, and the production of meaning in one's life. Both processes, which use the same word (identity), work in completely opposite ways. The identification conducted by the State is to identify, record, classify individuals, based on their biological nature or on the objective materiality of their history. That is why the state is always weakly positioned to talk about identity, because its perspective is very narrow. On the contrary, the production of meaning works with these inherited elements, but reformulates them constantly. Even more so as we have not only one story, but a thousand, entangled in us, and contradictory. It is we who choose a part of our past or an affiliation, in order to make sense at some point.

The third error relates to grounding. Every identity is constructed through a temporary grounding and reduction. This is necessary in order to create a meaningful and impeccable (i.e. simplistic) totality, which alone is responsible for authorizing action. Accordingly, this lends support to the perspective that identity might represent something fixed and stable (a perspective which keeps on fueling essentialist conceptions). These groundings, however, last, in fact, only a few moments, and are extraordinarily volatile. On the contrary, its openness and its permanent variations define the identity process itself, anchored in the present and developing future scenarios.

There would be a lot to say on each of these last two points. One such further elaboration would touch upon the ease with which the technical procedures of administrative identification (although easily definable) produce, through mixture, substantiation effects in the conceptions about identity. Another elaboration, concerning the grounding of identity, could confront further the difficulties that we have when we question and concede that identity is plural and malleable. As a matter of fact, the concessions made are, generally, extremely limited. The plural and malleable character is, as a matter of fact, infinitely larger, as I have demonstrated in my book, Quand je est un autre [When me is another one] (2008).

\section{Democratic - individualistic societies and the production of sense}

I prefer to emphasize here the first point. I have briefly mentioned that we should not link individual identities to the history of the individual (nor national identities to the history of a nation) and that the main process lies in the present, where we find the mechanism of meaning production and a totality endowed with meaning. But at the same time, the role played by identity in society is itself strongly influenced by history. Socially speaking, identity is a relatively new 
concept.

To explain briefly, it is necessary to return to the historical break between holistic societies and individualistic societies, as it has been described by Louis Dumont. This break (which should not be seen neither simplistic, nor linear) between two models of social functioning has been recently questioned in France, some claiming that the individuals in individualistic societies were not as free as one might think, and that they were probably more so in holistic societies. There is a misunderstanding which should be clarified regarding the confusion between the official rules of the game (it is on this point that the historical break operates) and the particular reality of the person. Now, there is nothing surprising that the individual is less free in democratic-individualistic societies than it imagines. It is even possible to extend the analysis to the paradox, by wondering, for instance, if individual autonomy does not logically lead to a more insidious normative production, more intense than in a holistic society, where institutions develop their program, by drawing the boundaries of the game. I will present a single example, based on one of my research. In May 1968, the Parisian demonstrators had launched this poetic slogan: 'Under the cobblestones, the beach!' They recalled the beach as an image of happiness, but above all, freedom. It is surely presented as very emblematic for these open spaces of advanced modernity where existence seems less constrained. Yet, the research has revealed the following paradox: as norms become less mandatory, people's main activity is to produce new ones, to the point of reaching the obsession of normality (Kaufmann, 1995). Paradoxically, the slightest difference is probably more examined than in a more disciplinary institution, because it is subtle and actively used in the continuous process of establishing norms. Freedom-based society is one in which, more than ever, norms are (discreetly) produced. It is certainly forbidden to forbid, and everyone has the right to make a wrong step. But one pays a discrete pressure which, in keeping it uncomfortable, must make him step back in line: 'Everyone does what one wants, but ...' The contemporary society invents a mode of functioning structurally based on a double language.

Louis Dumont himself (1983) had, however, warned us, so as to avoid any confusion: the holism/ individualism opposition does not refer to the existing individual, but to the representation model dictating the rules of functioning of a society. To simplify, let me say that the debate revolves around the following question: where is the meaning of good and evil, right and wrong defined? In the holistic society, individuals are caught up in collective frameworks, most of the time religious, which give them common responses. Their personal conscience is 'hung outside' (Vernant, 1996:226). Today, on the contrary, it is the individual himself, having to choose and choose again, in every field, between a thousand products, a thousand ideas, a thousand ways of doing things, a thousand moral principles or a thousand persons. With every choice the individual makes, even the tiniest, he must enroll it at the same time in a universe of overt meaning, which entails a totalizing propensity. 
Without the instantaneous production of such a 'belief', any action directed by consciousness becomes impossible (of course embedded automatisms are regulated in other ways). Such is the new working manner of social processes, which places the identity process at the center.

\section{The historical mutations of the identity issue}

In the primordial communities or in traditional society, the identity process has not occupied such central place and has not played such a driving role. It is of course conceivable to state with our current words that 'identities' existed, if we understand them by the unique characteristics of an individual or a group. Clearly, however, there was no problem of identity, in the sense of the modern, multifaceted and generalized interrogation, which characterizes contemporary societies. The identity process is intrinsically linked to modernity. During a first historical stage, notably from the 18th century on, it formed itself at the top of society, with the development of the statist bureaucracy, faced with uprooted people, or communities without territories. Administrative identification made it possible to control them. Thus identity papers were born, which later became generalized to the whole population. This has produced an inaugural intellectual confusion, with heavy consequences. As the entire reality of a person was, indeed, supposed to be concentrated in a few papers, identity was perceived as a simple and controllable fact. On the contrary, the new, contemporary evidence demonstrates that it is extraordinarily complex, unstable and intangible. The simplistic view of identity is understandable, and even necessary, from the perspective of the state. The problem is that it spread to individual points of view: the papers appeared to be summing up the essential elements of the person.

The first phase of modernity, which Peter Wagner (1996) so aptly qualified as 'organized modernity', was a kind of modernity without real modern identities, where individuals were socially constructed, without necessarily having to develop ontological interrogations, the persons who receive from institutions the sense of what still resembles a lot like a destiny, depart very little from the communitarian fingerprint of traditional societies. While everything changes at the top, at the bottom life continues by itself and unfolds in a predictable way. This continuity was broken for most of the population in the postwar period, especially around the $1960 \mathrm{~s}$, leading to individual identity interrogations. The rupture axis is, apparently, well known: the emergence of the subject, becoming (in theory) the master of his/her future. The social development pattern is now that of the democratic individual, free of its most diverse choices (each with his/her own truth, his/her morality, his/ her special commitment to social ties). However, this is only a pattern, ever more prevailing, of course, but not functional in its entirety. Let us take the example of reflexivity, the look onto oneself that everyone now increasingly engages into, fed by an enlarging mass of information conveyed by the media, whose central role in the second phase 
of modernity Ulrich Beck (2001) and Anthony Giddens (1987) underlined. But a full and permanent reflexivity is strictly impossible; life would become a hell populated by endless interrogations, ruining the capacity to act, since bodies can move only within a framework of evidences. We are therefore condemned to give meaning to our daily lives, in order to limit the infinity of possibilities. The more questioning intensifies, the more we need and we must, instead, nestle in our personal evidences. Identity is that which closes meaning and creates the conditions of action. Otherwise, the modern individual fails and falls into depression (Ehrenberg, 1998).

The identity process is a particular form of subjectivity at work, consisting of making, at every moment, a meaningful totality. For identity, the objective markers (our biological heritage, social and cultural) are not allpowerful in terms of identity, especially since they are not a homogenous block. We have numerous, often competing affiliations (world of one's job, family, sports club etc.), and we cross in the course of our existence various contexts that print traces in us: a region or a culture of adoption may replace the region or the culture of origin. Our social and cultural acquisitions are heterogeneous and, for certain aspects, contradictory. Oppositions cross them, forcing the subject to get involved. The initiative capacity of the modern individual forms mainly here, in this arbitration work, which mixes and chooses the elements which, later, will confer the meaning of life. The techniques used in this work are numerous and diverse. Some, like the narrative activity highlighted by
Paul Ricoeur (Ricoeur, 1990), settle on biographical unification and are focused on the past. Everyone tells the story of his life, by collating together scattered pieces. Others, less known, are instead turned to the immediate present or the future. We imagine very freely virtual identities in our common daydreaming. Faced with the reality, these self-images take the form of 'patterns of work' preparing the action, 'possible selves' analyzed with delicacy by Hazel Markus (Markus and Nurius, 1986). In contemporary societies, the action is increasingly filtered in advance by viewing oneself, which is nothing else but a display of identity. Rimbaud had already intuitively formulated it: I, as I, is continually another, asserting his subjective peculiarity by departures from the demands created by socialization (Kaufmann, 2008).

The forced works of personal autonomy are exhausting for the modern individual. They produce very discriminating situations and new inequalities. Persons whose social position guarantees a certain recognition, and who belong to multiple and diverse networks, have the opportunity to play different faces of their identity. On the contrary, those who feel more advantaged in terms of defense, threatened by stigmatization or simply a loss of self-esteem, are doomed to retreat into cocoons of protection, which separate them from the rest of the world by granting them an answer, obvious and unique, in the questions of life. To lock oneself into significant totalities, which set the identity, is, undoubtedly, a religious belief. We have entered into the era of the irresistible rise of identity beliefs. 
The essence of any identity is religious

These often take a religious form. Finding religion here is only superficially a surprise. The so-called 'religious revival' is indeed driven by the revolution of identity. For the best, such beliefs provide comforting ethics to confused individuals. For the worst, however, the reformulation of traditional communities constructs totalitarian and belligerent collective identities. Religion, which used to be a significant structuring instance in society, socially conferring the meaning of life in the past, is today more and more internalized as a personal belief (Hervieux-Léger, 1999). By relieving, to a small extent, the individual of anxiety and the fatigue of being oneself, it could, in this new, therapeutic function, assure him his psychological equilibrium, calm and serenity. Besides, religions multiply efforts in the direction of peace and tolerance. The passage through the personal interiority, however, renders the signification system potentially unstable and volatile: in some contexts it takes much less peaceful forms. Identity is constantly on the lookout for the devilish idea of absolute totality, all the more reassuring as it becomes simplistic and exclusive. Thus, the religious corpus, by separating itself from the everyday society, is ideal for this possible drift, taking the form of fundamentalism.

The need to believe in the personal identity and values it makes possible, cannot be reduced, nevertheless, to the religious sphere. Everything is good to be taken as a support for the closure and securing of the meaning of life. This explains, for example, the massive development of mundane passions in contemporary societies (Bromberger 1998). Cultural activities, sports associations etc. - the modern individual multiplies the micro-commitments that provide material for petite secular beliefs, punctual beliefs that underpin a specific cosmology and that cluster on oneself, offering guidance in various situations one encounters. Nevertheless, it is constantly marked by the danger that a unique belief does not offer closure, especially in situations of social or personal fragility. Any identity whatsoever contains totalizing propensities, threatening for the autonomy of the individual.

The slippage towards this risk depends on the number and diversity of 'possible selves', a consequence of social and cultural resources. When the game of available identities is rich, tabulations are brief and succeed one another. The individual turns into a manipulator of his/ her transitory micro-totalities, and develops necessarily a reflective distance towards his changeable selves. Conversely, when the game is limited, the totalizing process is repeated (and, necessarily, hardened); the interpretive grid becomes permanent, and may, eventually, end up enclosing the entire personality. The aggregation is not particular for a given moment or context, but defines the individual himself. The closing- up mechanisms deepen the social stigma and undermine self-esteem. The entire universe becomes, then, foreign, incomprehensible and hostile. It is only the clinging on a few obsessive ideas and the oppositional energy against all kinds of enemies that protects against a 
personal psychological implosion. The pay-off consists of major social risks. The growing identity affirmations (whose radical model is fueled by religious fundamentalism) outline a very uncertain future for the stability of our societies.

The Enlightenment-based modernity was believed to be founded on Reason, whose defeat of emotional darkness and mysticism was announced as an inevitable outcome. The latest social developments, however, offer every day increasing illustrations that rationality must, in fact, deal with a new universe of belief, an universe which it, paradoxically, induces, as it continues to grow. Contemporary beliefs are less a residue of ancient times, than a product of the most advanced modernity. A new religion tends to become universal, based on faith in oneself as an unquestionable significant totality. Everyone works hard to believe in what grounds one's existence. It is this transformation of civilization that explains the obsessive rise of the theme of identity.

\section{The inversion of the principle of affiliation}

In a traditional society, identity is a weak issue because objective individuality and subjective identity converge. Identity hardly appears as a question, since the meanings of life and action are given by the objective reality and driven by institutional frameworks. In the first phase of modernity, convergence is still large, and confusion may occur, since identity is still granted, for the most part, by various social supports. The radically new phenomenon established half a century ago (the reference to the model of the autonomous individual) reverses the situation. This period witnesses a split and a growing divergence between objective individuality and subjective identity. It also witnesses an extraordinary growth of subjective identity process. This growth not only indicates the direction of present thought and action, but participates in the making of the future socialization frameworks. It is, as a matter of fact, the total sum of connections between the objective and the subjective, which is reformulated by the mutation of identity. This may be particularly well illustrated by the question of affiliations.

Traditionally, affiliations are a really simple way to describe: that individual is part of that group (family, corporation, etc), a fact that assigns for $\mathrm{him} / \mathrm{her}$ a place, a role, a moral framework, a system of thought and action. The individual is a 'member' of this group, just like the arm is a part of the body. The heritage of this type of affiliation remains, mentally, very strong, while we only slowly, with a temporal gap, become aware of the inversion which has been going on: more and more, it is the individual who chooses no longer to 'belong' to a particular group, but to register to it, for a period that one will consider necessary. The process has been described by Durkheim or Tönnies a long time ago. While it was a structural and defining framework for the individual, affiliation becomes a cultural and relational resource. It is essential for building self-esteem, as one is nothing without relating to others. It is also reversible. The individual is not defined by its affiliations (or, more 
precisely, by one or another of one's diverse affiliations); one's affiliations are important only to the extent that the individual reactivates and displays them.

Market driven globalization passes through social formations which are in very different positions with respect to these two types of affiliation. The holistic or quasi-holistic structuring remains present, particularly in the Global South. This consideration, however, must dispose of a schematic and linear evolutionism according to which, at the heart of the most advanced modernity, the identity process may nourish the reinvention of organic affiliations. The appropriate model is the sect, which addresses vulnerable individuals, and restructures them psychologically by integrating them, at the cost of the loss of their autonomy.

Unlike traditional societies, the current holism spread by sects constructed reality and social integration out of a fictional imaginary. Bearing, in a way, the legacy of the Manichaean religions, they invent a bright world (at least for them), by insulating themselves drastically of the existing world and by refusing it, or even dreaming to destroy it, as some fundamentalist religious sects have shown. Islamism, for instance, refers to an ideal community, the ummah, which is, in fact, only an intangible abstraction, not in accordance with traditions themselves. In doing so, it establishes a doctrine which defines lists of requirements, a closed set of rituals, obligations and prohibitions (Roy, 2002). Placed inside a wellcontrolled network, closed and isolated from the rest of the world, such doctrines may tip up the individual in an inclusion similar to the ancient regime of membership, by abandoning the capacity of independent judgment.

\section{The historical shift of the national idea}

Even if one sets aside this sectarian mechanism likely to obscure the analysis, the comparative analysis of the two regimes of affiliation does not become any clearer. In many cases, indeed, particularly in countries economically, socially and culturally dominated, it is very difficult to say whether the context requires identification based on the model of the autonomous individual or encourages collective matters. Between, the interethnic conflicts leading to genocidal attempts (condemned by the international community) on the one hand, and the popular movements for liberation from colonialism and oppression of any kind (on the contrary, recognized by the UN) on the other, each group engaged into conflicts seeks to defend its particular situation. The question to be solved is always the same: does the quality of the political problem justify the replacement of individual identities by collective identification? Do individuals register first in this wide perimeter of identification in order to define themselves personally? The answer is often more complex as globalization entered into societies not only culturally different, but which also experienced history at a different pace. Collective identifications, notably the national idea, represent, in a way, the first historical phase forced by the process of identity. 
This is how it was experienced in Europe, especially at the beginning of the $19^{\text {th }}$ century. The cultural and linguistic foundation of national entities was, however, less obvious than today. It was largely designed and cobbled together with mixed material. In Italy, for example, the intellectuals of the Risorgimento were aware that that they were inventing a new social form which was overtaking numerous local powers. Like in all European nations, the dream was to discover (in the language, culture, history) a natural essence legitimizing this new whole. It was also about representing the nation as a living being (Noiriel, 2001). It also meant to experience it as a totality as perfect and carnal as the laws of biology, clearly separated from other nations. Spirits heat up around this other concept hardly less vague than identity. In France, the idea crystallized in the fire and the blood of the Revolutionary War, then during the Napoleonian conquests, which, at their turn, aroused the nationalism of the attacked people. Such violent events do not explain well the tonality of the national idea of the early $19^{\text {th }}$ century. It was very different from the aggressive and narrow-minded nationalism that would develop later. It aimed in fact, breaking with tradition, to forge an instrument of collective self-determination. To lay the foundations for an institutional modernization that was to generate the individual autonomy in the second half of the $20^{\text {th }}$ century.

The deal is completely different today for the people claiming selfdetermination. The national idea, fattened by a form of identification primarily collective, enters in conflict with multiple forms of individual emancipation. These forms are circulated by economic and cultural globalization, which permeates every space, inclusively in the most archaic communities, through instruments as diverse as silver or television.

Dominated cultures are trapped, in a way, by the raffle of history and the victims of an injustice. Torn between two ways of asserting identity, they try to reduce dissonance, to challenge the models of modernity imposed by the West, and to propose alternatives. They are heading particularly in the sense of an autonomy that would be based on collectives or, in other words, on a person organically connected to the social body and its culture. The critique, easy and efficient, concerning the model of the individual which founds the science of economics (the calculating individual animated only by personal interests), finds, on the contrary, very quickly its limits in relation to the model which grounds human rights or the principles of a democracy without concessions. Most importantly, the alternative proposals entangle themselves in multiple contradictions. The connected individual is mainly the individual linked to his family, and to traditions that constitute it. This, for women, inevitably means to be subjected to a subordinate role. All the debates around the veil, for example, are traversed by these contradictory aspirations.

\section{The paradox of national identity}

Neither have we, in Europe, fully consumed the issue of national identities, and this represents a paradox that I would like to try 
to explain. It is a paradox because the frames of socialization are less and less specifically national. The market economy is globalized, its mathematical and financial derivatives as well, any regulation is only very weekly operating in a uniquely national space: we have proofs of it every day. A similar analysis could be made to the globalization of culture and the role of the Internet, which has no borders; or on the role of supranational institutions, especially European institutions etc.

To this description of these objective frameworks, it should be added that the national reference is extremely rare in the lived processes of identification, as they occur in Europe today. When belongings are occasionally reactivated as a resource, it is most often the family, groups of friends, clubs and various associations, or very local territorial inscriptions. Not only is the nation only marginally invoked, but when invoked it is more in an indirect and abstract manner; most often for sport confrontations. A football game stages a confrontation between 'us' and others, experienced by proxy. If the game is international, 'we' takes a national form, and is materialized by a hymn and flag. The supporter becomes for some minutes 'French' or 'Romanian'. But it is necessary to understand that it is about a simple instrument of an identification game, whose main principle is the organized confrontation between 'we' (which, fundamentally, indexes an 'I') against 'others'. Identification may function just as well for fans of any club. The only changes are the songs and the colors of the flag.

National identification becomes even more abstract and volatile as its objective foundations become weak. Why say, then, that we are not through with it? Precisely because of this abstract volatility, that may make it relatively uncontrollable. We had an impressive illustration in France, with the launching by the government of a 'Grand Debate on the national identity.' Originally launched as a political maneuver to rally the voices of the extreme right party, the National Front, the maneuver was quickly turned into a veritable diabolic Pandora's Box, out of which arose, through confusion, various manifestations of racism and intolerance. Faced with the impossibility to define this famous 'national identity', an implicit opinion marked the cleavage between the 'real French', 'rooted' for several generations, and others (assimilated to immigrants), which had to bend to values and customs of the 'host country.'

This deplorable event, which fortunately has remained essentially in the register of trag-comedy, is not an isolated case. The extreme-right groups which suddenly, here or there in Europe, see their share of the vote growing, cultivate aggressive nationalism and often refer to 'self-defining' references, sometimes without even adding any word to qualify. At the heart of this vision, identity means 'us' against all others. National identity has become a concept so abstract and volatile that its more radical supporters no longer even try to define it.

The major danger for democracy, however, does not come probably from there, but from more unexpected and insidious forms. While the share of the electoral votes for extreme right parties reaches stagnates as soon as 
they display overtly violent ideas, a new type of flamboyant and media populism, well illustrated by Silvio Berlusconi in Italy, exemplifies, on the contrary, its great adaptation ability to the new political game, dominated by images and emotions. The usage of national identity is particularly remarkable because it does not display itself as such. Drawing some of his references from football (Berlusconi is, also, the president of an important club), it stages the identification play as a competition of 'us' against others, as shown, for example, by the name of his political party for some years: Forza Italia! ('Go Italy!').

I stressed at the beginning of this article the necessity, which seemed essential to me, to take into account the fundamentally subjective character of the identity process. This seems to me even more urgent when one considers the possible alternatives of uses of national identity. The divergence deepens between the objective frames of socialization, increasingly transnational, and the subjective volatility of self-defining crystallizations. Thus, precisely because the objective substrate of national identity weakens, its eruptive movements (occasioned by crises caused by extremely various reasons) become particularly uncontrollable and should be closely watched.

\section{References}

Beck, U. (2001) La société du risque. Sur la voie d'une autre modernité. Paris:

Aubier.

Bromberger, C. (1998) (éd.) Passions ordinaires : du match de football au concours de dictée. Paris: Bayard.

Dumont, L. (1983) Essais sur l'individualisme. Une perspective anthropologi que sur l'idéologie modern. Paris: Le Seuil.

Ehrenberg, A. (1998) La fatigue d'être soi. Dépression et société. Paris: Odile Jacob.

Giddens, A. (1987) La constitution de la société. Eléments de la théorie de la structuration. Paris: PUF.

Goffman E. (1975) Stigmate. Les usages sociaux des handicaps. Paris: Minuit. Hervieux-Leger D. (1999) Le pèlerin et le converti. Paris: Flammarion.

Hirschman A. (1980) Les passions et les intérêts. Justifications politiques du capitalisme avant son apogee. Paris: P.U.F.

Kaufmann J.-C. (1995) Corps de femmes, regards d'hommes. Sociologie des seins nus. Paris: Nathan.

Kaufmann J.-C. (2008) Quand je est un autre. Paris: Armand Colin.

Markus H. and Nurius P. (1986) 'Possible selves', American Psychologist, 21(9): 954-969.

Noiriel G. (2001) Etat, nation et immigration. Vers une histoire du pouvoir. Paris:

Belin.

Ricoeur P. (1990) Soi-même comme un autre. Paris: Le Seuil. 
Roy O. (2002) L'islam mondialisé. Paris: Le Seuil.

Vernant J.-P. (1996) L'individu, la mort, l'amour. Paris: Folio-Histoire, Gallimard. Wagner P. (1996) Liberté et discipline. Les deux crises de la modernité. Paris:

Métailié. 
